\title{
A LÍNGUA QUE A ESCOLA COMEU
}

\author{
Mariana de Oliveira Wayhs ${ }^{1}$ \\ Elizabeth Fontoura Dorneles²
}

\begin{abstract}
RESUMO
A constituição do sujeito criança na relação com a personagem Bruxa dos contos de fadas é o tema deste estudo. $O$ objetivo central da pesquisa é desvelar o funcionamento discursivo a partir da análise dos efeitos de sentido constituídos na relação personagem Bruxa/sujeito criança e os impactos em termos de linguagem e comunicação. A materialidade de análise consta de entrevista semiestruturada com crianças de 6 a 11 anos, filhos dos catadores do Projeto Profissão Catador da Unicruz, e gravação dos áudios e transcrição para a formação do arquivo do analista. Partindo das sequências discursivas selecionadas, são aplicados os procedimentos teórico-metodológicos da Análise de Discurso Francesa (AD). Ao aprofundarmos os estudos discursivos, percebemos que a Bruxa, inscrita nas condições de produção das crianças entrevistadas, é a da inquisição, a demoníaca, que, na realidade, acaba se materializando no silenciamento do sujeito criança, consequência do trabalho com a língua portuguesa a partir de uma perspectiva imaginária e não fluida.
\end{abstract}

Palavras-chave: Análise do discurso. Efeito Bruxa. Cultura. Sociedade moderna. Criança.

\section{THE LANGUAGE THE SCHOOL GAVE}

\section{ABSTRACT}

The constitution of the subject child in relation to the Witch character of fairy tales is the theme of this study. The central objective of the research is to reveal the discursive functioning from the analysis of the effects of sense constituted in the relation Witch character/child subject and the impacts in terms of language and communication. The materiality of analysis consists of a semi-structured interview with children from 6 to 11 years old, children of the collectors of the Profession Project Catador of Unicruz, audio recording and transcription, for the formation of the analyst archive. Starting from the selected discursive sequences, the theoretical-methodological procedures of the French Discourse Analysis (AD) are applied. As we deepen the discursive studies we realize that the Witch inscribed in the conditions of production of the children interviewed is that of the inquisition, the demonic, that, in reality, ends up materializing in the silencing of the child subject, consequence of the work with the Portuguese language from a perspective, not fluid.

Keywords: Discourse analysis. Witch Effect. Culture. Modern society. Child.

RECEBIDO EM: 3/8/2018

ACEITO EM: 14/5/2020

\footnotetext{
${ }_{1}$ Autora correspondente. Universidade de Cruz Alta - Unicruz. Rodovia Municipal Jacob Della Mea, s/n, km 5,6 - Parada Benito. CEP 98020290. Cruz Alta/RS, Brasil. http://lattes.cnpq.br/0972239037645535. https://orcid.org/0000-0002-5074-9699. mawayhs@unicruz.edu.br

2 Universidade de Cruz Alta - Unicruz. Cruz Alta/RS, Brasil. http://lattes.cnpq.br/2511364442835152. https://orcid.org/0000-0001-69501653
} 


\section{PREPARANDO A POÇÃO}

Vários ingredientes compõem o caldeirão daqueles que ficam à margem dos processos educacionais: segregação, exclusão, limitação da voz. O trabalho docente a partir da língua imaginária, recorrente numa escola ainda aprisionada aos preceitos tradicionais que entendem o aluno como uma simples "esponja" no processo ensino-aprendizagem, contribui para esse cenário, uma vez que, como maior patrimônio de mobilidade social, dá ao sujeito a ideia de não estar qualificado, apto ou de não ter o direito de utilização do seu próprio idioma.

Ao falar o sujeito se significa, constitui a sua identidade, segundo Orlandi (1996, p. 28). O discurso, dessa forma, acontece na prática da linguagem e não existe sem o sujeito, incompleto e assujeitado, o qual deixa nas marcas linguísticas traços da sua identidade. O sujeito inscrito numa Formação Discursiva não é o indivíduo, mas o efeito do coletivo constituído em determinadas condições de produção.

Desse modo, a potência das palavras e do poder/dever dizê-las permeia as relações sociais e define o lugar dos corpos no espaço.

O peso de não entender a língua como fluida, algo vivo, que está nas ruas e contempla as experiências e modo de ser de cada um, nas mais diversas manifestações do sujeito, coloca a participação social em risco. Por isso, este estudo parte da importância de avaliar a percepção do sujeito criança acerca da personagem bruxa, como forma de verificar o seu acesso à leitura, à interpretação e à ressignificação dos contos no imaginário infantil, posto que é na infância que se projeta a dimensão do público ledor e sua relação com a escrita na idade adulta.

A escolha da Bruxa para essa análise encontra justificativa na afirmação de Bettelheim (1996) sobre os contos de fadas, pontuando-os como leituras extremamente saudáveis, levando em conta que apresentam soluções de forma simbólica para o enfrentamento de problemas. Considerando que a personagem escolhida concentra uma carga de obstáculo entre o desejo e a dificuldade de alcançá-lo, entre o possível e o impossível, entre a inércia perante o medo e a coragem de enfrentá-lo, a investigação sobre o que a Bruxa reflete no imaginário infantil é um terreno fértil.

A fim de chegarmos ao arquivo do analista, à materialidade linguística analisada, utilizamos a entrevista semiestruturada com crianças entre 6 e 11 anos pertencentes às famílias do Projeto Profissão Catador da Universidade de Cruz Alta. O áudio foi gravado e transcrito. As sequências discursivas foram analisadas a partir dos procedimentos teórico-metodológicos da $A D$, levando a direcionamentos não imaginados no início do estudo, conforme veremos adiante.

O Projeto de Extensão "Profissão Catador II" da Universidade de Cruz Alta, patrocinado pelo Programa Petrobras Socioambiental, "contribui com a construção de alternativas coletivas para a organização dos Catadores de Cruz Alta, através da criação de associações para a coleta, separação, armazenamento e comercialização de materiais recicláveis". Conforme a Assessoria de Comunicação, 
A segunda edição do Projeto, aprovada pela Universidade de Cruz Alta no ano de 2014, tem como finalidade constituir uma rede de comercialização de materiais recicláveis, fortalecendo a organização econômica e social dos catadores do município de Cruz Alta e expandindo o trabalho de organização da atividade de catação para os municípios de Tupanciretã, Júlio de Castilhos e Salto do Jacuí. Tal proposta deriva de projetos de extensão desenvolvidos pela Unicruz desde o ano de 2006, dentre os quais do Projeto Profissão Catador I, patrocinado desde 2010 pelo Programa Petrobras Desenvolvimento e Cidadania. Através da implantação do Profissão Catador I foram criadas e organizadas no município de Cruz Alta quatro associações de catadores nos Bairros: Funcionários, Acelino Flores, Jardim Primavera 2 e Planalto. Ainda, foi criada a CENCOR (Central Regional de Comercialização de Recicláveis), com o objetivo de fomentar esta comercialização através da negociação com as indústrias que reciclam materiais coletados pelos catadores. A partir daí houve um aumento significativo na renda dos trabalhadores, além das novas adesões de associados junto ao projeto.

O contrato de patrocínio com o Programa Petrobras Socioambiental, firmado em 2014, com o Projeto Profissão Catador II, promoveu o fortalecimento das associações já constituídas e a expansão do projeto com capacitações, compra de materiais de trabaIho e mais instalações com maquinário para a realização das atividades. Além da Petrobras, o Projeto recebeu aporte financeiro da Secretaria Nacional de Economia Solidária (Senaes), do CNPQ, da Rede de Parceria Social do Rio Grande do Sul e, atualmente, conta com o apoio da Fundação Banco do Brasil. Além disso, a Assessoria de Comunicação salienta que

A Universidade de Cruz Alta e as demais instituições e entidades parceiras têm agido no sentido de fortalecer as iniciativas de coleta seletiva solidária, nas quais os catadores protagonizam os processos de organização para geração de trabalho e renda. Essas articulações colaboram na viabilização do compromisso com a realidade social regional e com as exigências societárias, no que se refere à contribuição em relação à inclusão social, ao desenvolvimento econômico, social e à defesa do meio ambiente. Uma conquista nesse percurso foi a contratação do Projeto Profissão Catador para prestação do serviço de coleta seletiva em 44 bairros do município de Cruz Alta, a partir de termo de fomento com o poder público municipal, assinado em 2019. Esse acontecimento ampliou o espaço da classe trabalhadora nas associações, bem como proporcionou o aumento da renda e maior respeito e visibilidade aos profissionais da catação. Mas ainda há muito o que se conquistar em termos de justiça econômica e social.

À margem dos direitos sociais e com acesso limitado à educação, os catadores, antes do referido Projeto, ficavam expostos à exploração de atravessadores e à invisibilidade social que, segundo os integrantes, os confrontavam com a autoidentificação com o próprio lixo.

Contribuir com desenvolvimento das comunidades atingidas pelo Projeto Profissão Catador, dando voz às crianças que pertencem às famílias dos catadores, passou a ser uma das grandes finalidades dessa investigação ao nos depararmos com uma realidade preocupante, apontada anteriormente. Já no início das entrevistas constatamos a condição de silenciamento das crianças, fazendo com que o nosso objetivo inicial fosse 
reorientado para a análise dos efeitos de sentido dessa ausência de "voz", o que levou a uma reflexão, a partir de Orlandi, sobre o trabalho voltado à concepção imaginária de língua na escola.

Com a institucionalização da educação pela escola, abordada por Saviani (2008, p. 7), "as relações sociais passam a prevalecer sobre as naturais, estabelecendo-se o primado do mundo da cultura (o mundo produzido pelo homem), sobre o mundo da natureza." Nessa etapa histórica, em que o currículo do Aparelho Ideológico Escola serve ao mundo do trabalho a partir de disciplinas predefinidas, a língua materna vira a "inquisidora" do processo de ensino-aprendizagem, limitando a mobilidade social dos que não se enquadram nos padrões esperados, conduzindo-os à "fogueira", uma vez que, como afirma Cecília Meireles, "a liberdade das almas, ai com letras se elabora.

\section{ALGUNS RITUAIS DO ANALISTA EM AD: METODOLOGIA}

Quando Pêcheux questiona as formas de leitura, colocando em pauta a não transparência da linguagem (ORLANDI, 1996), cria o gesto de interpretação, sugerindo um novo olhar para os textos do cotidiano, levando em consideração a espessura histórica e linguística.

Diante dessa proposta, um dos pontos de partida do analista em AD é a formação de seu arquivo, considerando que "nos estudos discursivos, não se separam forma e conteúdo e procura-se compreender a língua não só como uma estrutura, mas sobretudo como acontecimento" (ORLANDI, 1999, p. 19). Sendo assim, a AD vai além das fronteiras da linguística, do marxismo e da psicanálise (ORLANDI, 2003).

Com base nesses princípios, a fim de obter a materialidade linguística para a análise, foram entrevistadas crianças entre 6 e 11 anos - familiares dos catadores do Projeto Profissão Catador da Unicruz -, a partir de um roteiro de entrevista semiestruturada, contemplando temas como: o conhecimento dos contos de fadas, os tipos de contos de que mais gosta, quem são os personagens bons dessas narrativas e os motivos de serem do bem, quem são os maus e os motivos dessa maldade. O questionário foi desenvolvido de forma a permitir que as crianças falassem livremente sobre o assunto, não limitando as respostas para sim ou não. Algumas questões abordadas foram: $O$ que são os contos de fadas? O que é viver feliz para sempre? Quem é a bruxa dos contos de fadas? O que a bruxa faz? Você prefere a princesa ou a bruxa e por quê? Vale salientar que as questões serviram de roteiro para orientar a condução das entrevistas, mas os sujeitos tiveram liberdade para falar o que consideraram interessante acerca do tema pesquisado.

As conversas com as crianças foram realizadas nas bibliotecas das escolas individualmente, e o entrevistador não conhecia as crianças. $O$ acesso aos entrevistados foi concedido pelos pais após a realização de reuniões com os catadores nas associações, acompanhadas da assistente social do Projeto Profissão Catador, para explicar detalhadamente o objetivo da pesquisa, o roteiro de perguntas e o Termo de Consentimento Livre e Esclarecido. 
Os áudios das conversas foram gravados e transcritos. Os procedimentos de contato com o público pesquisado somente foram realizados após aprovação do Comitê de Ética em Pesquisa da Unicruz, número do CAAE 39462514.6.0000.5322.

No momento das entrevistas, para iniciar, a entrevistadora, que possui curso de teatro e recreação, procurou se apresentar e criar um clima propício à imaginação, contando um pouco de sua própria vivência com os contos de fadas. Após conseguir interagir com a criança, iniciava o roteiro de perguntas, a partir do qual percebeu que os entrevistados não têm acesso aos contos fora do ambiente escolar e que, mesmo dentro das Escolas, os momentos de leitura são muito limitados.

Após as transcrições das entrevistas iniciais foram realizados sucessivos recortes das pistas linguísticas que mais causaram inquietude para formar o arquivo de análise a partir dos procedimentos teórico-metodológicos da AD: seleção das sequências discursivas, determinação das pistas linguísticas a partir das quais será examinado o funcionamento discursivo, apresentação das condições de produção, análise das pistas baseada em recursos da linguística, explicitação da produção de efeitos de sentido e determinação do funcionamento discursivo.

\section{RELAÇÃO SUJEITO CRIANÇA/PERSONAGEM BRUXA: Olhares Para o Arquivo do Analista}

Que Bruxa é essa que assusta, que está presente como personificação do mau nos contos e músicas? Que demônio a igreja conseguiu fabricar na memória coletiva? Como esse ser está alocado no imaginário infantil?

Essas são questões que responderemos no decorrer da análise. Agora, lançaremos nossos olhares para as entrevistas realizadas com as crianças - familiares dos catadores do Projeto Profissão Catador da Universidade de Cruz Alta.

O Outro é parte integrante da constituição do sujeito e de seu discurso (CORACINI, 2003); o Outro é celebrado em nossa identidade, e, mesmo que repudiado, está presente na negação.

Esses processos de identificação/desidentificação escapam à consciência. Dizem respeito à exterioridade, aos diversos discursos que fazem parte da nossa existência e com os quais criamos vínculos ou afastamentos, dependendo da nossa formação ideológica e social, que estão presentes nas Formações Discursivas (FDs).

Dessa forma, "a ilusão constitutiva do eu, que assim se assume por imaginar-se fonte de sentido, apaga nesse processo a possiblidade de o sujeito identificar a causa em si mesmo" (DORNELES, 1998, p. 88). A forma-sujeito é resultante de vários aspectos que compõem a identidade, entre eles daquilo que nos pré-constitui e passa a integrar nosso interdiscurso. Conforme Pêcheux (1995, p. 164),

o "pré-construído" corresponde ao "sempre-já-aí" da interpretação ideológica que fornece-impõe a "realidade" e seu "sentido" sob a forma da universalidade ("o mundo das coisas"), ao passo que a "articulação" constitui o sujeito em sua relação com o sentido, de modo que ela representa, no interdiscurso, aquilo que determina a dominação da forma-sujeito. 
O sujeito, mesmo interpelado por diversas FDs, estará filiado àquela que o assujeitou, pois "a identidade só se concretiza pela separação, afastamento desse todo" (DORNELES, 1998, p. 90). Aqui se estabelece a relação contraditória entre o um e o múltiplo; é preciso silenciar esse múltiplo para que o um permaneça (ORLANDI, 1995).

A memória do nosso saber e as filiações de sentidos compõem a nossa identidade; por isso o sujeito não é origem em si; a cultura é constitutiva desse sujeito, assim como a ideologia. Não podemos pensar em cultura como processo exterior que se impõe sobre o sujeito, mas verificar como o interior e exterior incidem no desenho da Formação Discursiva por meio dos processos de identificação/desidentificação.

Nesse processo está a escola e a sua função social. Com Saviani (2007, p. 158) vale lembrar que o modo de produção capitalista faz surgir uma nova relação entre trabalho e educação, que predetermina as posições sociais dadas:

Trata-se da sociedade contratual, cuja base é o direito positivo e não mais o direito natural ou consuetudinário. Com isso, o domínio de uma cultura intelectual, cujo componente mais elementar é o alfabeto, impõe-se como exigência generalizada a todos os membros da sociedade. E a escola, sendo o instrumento por excelência para viabilizar o acesso a esse tipo de cultura, é erigida na forma principal, dominante e generalizada de educação.

Quando abordamos uma escola que cala, vários aspectos transitam ao redor desse assunto: a segregação dos corpos biológicos no espaço pelo poder do capital; o processo de autoidentificação como ser que pode/deve estar na escola; os pré-julgamentos dos professores, que, muitas vezes, definem em quem investir ou não no processo de ensino-aprendizagem; o sistema educacional como um todo, as injustiças socioeconômicas das etapas históricas e os reflexos nas estruturas educacionais.

Nesse contexto estão os filhos dos catadores, que estudam em escolas de bairros pobres, próximas às associações, tendo como realidade a renda média familiar em torno de $\mathrm{R} \$ \mathbf{7 0 0 , 0 0}$ por mês, além dos programas socioassistenciais do governo, em que são incluídos com o auxílio das assistentes sociais do Projeto. As crianças residem em moradias, muitas vezes, precárias, algumas sem banheiro, nas quais todos os moradores, em média cinco pessoas por família, dormem no mesmo ambiente. Nesse espaço convivem com variadas dificuldades, que impactam diretamente nos resultados escolares e no não acesso à leitura e à brincadeira: fome; falta de infraestrutura para higiene pessoal; falta de roupas adequadas para a estação; ausência dos pais no turno inverso da escola para acompanhamento das atividades; analfabetismo dos membros mais maduros do grupo familiar; casos de alcoolismo e violência doméstica; casos de doenças mentais de familiares; acesso ineficiente a serviços de saúde; e, em alguns casos, as crianças já passaram por casas de passagem.

Tendo em vista a historicidade dos sujeitos pesquisados, procederemos com a análise das pistas linguísticas a partir das posições-sujeito identificadas na relação sujeito criança-personagem Bruxa. 


\section{A criança e a Bruxa: a legitimação da paráfrase - PS1}

A partir do início da era cristã, a Bruxa é divulgada para a sociedade como a ponte entre a terra e o demônio, como uma espécie de promotora de seus desejos no mundo terreno, e, por isso, por se configurar como o espírito do mal materializado em mulher, deve ser punida, perseguida, queimada e, acima de tudo, temida.

Mais uma vez na história a cultura aldeã é dizimada pelos Aparelhos Ideológicos do Estado (AIEs) ${ }^{3}$, e essa perseguição, em particular, além de culminar com a morte de inúmeros inocentes, estigmatizou a feiticeira, perpetuando-a como ignóbil na memória coletiva, posição que perdura há séculos e está fortemente marcada na literatura infantil.

A partir de inúmeras edições dos contos de fadas, especialmente nas releituras dos irmãos Grimm acerca dos contos de Perrault, os quais incorporaram o mágico e o sobrenatural às lendas populares que cercam a floresta e os vilarejos na Idade Média, o maniqueísmo é difundido na luta do bem contra o mal, e esse mal, muitas vezes, é representado pela Bruxa, constituindo as Formações Discursivas das crianças de hoje, como é possível perceber na Posição-sujeito Bruxa demoníaca - PS1. Essa PS é sustentada no discurso em três vertentes que a consagram como tal: na sua capacidade de ser má (conduta social), na sua feiura (estética) e na sua relação com mundo da fantasia (poderes sobrenaturais).

\section{A conduta social da Bruxa}

Quando questionadas sobre o conceito que faziam da Bruxa, ou seja, se ela era boa ou malvada, a maioria das crianças entrevistadas respondeu:

$\mathrm{Sdr}^{4} 31$ Feia, pega, bota no caldeirão. Ela arródia. Ela come.

Sdr 2 Ela tem a varinha dela, ela coloca a gente dentro do caldeirão, ela acende o fogo, quema, ela mata as crianças.

Sdr 3 Ela bota a gente no caldeirão. Ela meche pra fazer bruxaria.

Sdr 4 Pesquisadora: - 0 que ela faz pras crianças?

Criança: - Tudo de mal.

Sdr 5 Pesquisadora: - E o que as bruxas fazem nessas historinhas que tu leu?

Criança: - Maldade.

Sdr 6 Ela faz feitiço pra enganá. As pessoa acaba ficando mal.

Sdr 7 Pesquisadora: - Tu conhece a bruxa?

Criança: - Conheço ela, é muito malvada.

Como é possível perceber, o processo de paráfrase de edições de alguns contos de fadas em que a Bruxa é ruim está presente. A ideia de uma bruxa demoníaca com poderes do mal é recorrente nas entrevistas, considerando que a paráfrase, para a AD, é a reiteração de sentidos existentes no interdiscurso, ou seja, em uma FD (INDURSKY, 2003). A relação com a exterioridade marca-se pela aliança com discursos que têm a Bruxa como um ser medonho, capaz de produzir os mais diversos tipos de maldade,

3 AlEs - Aparelhos Ideológicos do Estado, conforme Althusser (1985).

4 Sdr-Sequência Discursiva 
concretizando-se como uma ameaça para o mundo dos "bons", o que sustenta uma visão binária dominante na nossa cultura. Maniqueísmo presente em vários contos de fadas.

As crianças na PS1 atribuíram à Bruxa poderes reais e mágicos. Poderes reais que fazem parte do "plano terrestre", como colocar uma criança no caldeirão, queimar uma criança, comer uma criança, envenenar uma criança. Poderes que um adulto muito mau poderia ter, um adulto como a feiticeira, a mulher camponesa, a mulher pobre, que, na inquisição, foi transformada em Bruxa. Também, conferiram à Bruxa malvada poderes mágicos, como transformar pessoas em animais com uma varinha. Essa relação entre humano e mágico, ambos praticantes de uma maldade extrema, retoma a paráfrase da Bruxa demoníaca, inserindo a bruxaria no plano mais obscuro da percepção humana: um ser humano tão ruim, tão perverso, que é capaz de se utilizar de magia negra para matar criancinhas em razão da sua aliança com o diabo; devemos ter muito medo da Bruxa, devemos queimar a Bruxa antes que ela pratique sua maldade.

Para além dos textos das sdrs podemos visualizar esses efeitos de sentido presentes na relação personagem bruxa/sujeito criança. O entorno constitutivo desse sujeito e suas condições de produção (crianças que não têm acesso amplo e frequente à diversidade da literatura infantil, a edições mais modernas dos contos, bem como desenhos animados que promovem uma visão diferenciada da Bruxa) não permitem a relatividade na relação com essa personagem; por isso ela é malvada, discurso que reproduz a imagem da Bruxa da inquisição.

A Bruxa está, para as crianças entrevistadas, depositada no interdiscurso como ruim, constituição de um estereótipo construído e sustentado na história, e quando questionadas sobre a possibilidade de ela ser boa, a maioria dos sujeitos mantém a posição de que ela é má, consolidando a investigação da interface do materialismo histórico, "já que a história intervém na língua e no processo de constituição dos sentidos" (FERREIRA, 2010, p. 21).

Voltando para as sequências discursivas (srds) expostas, o cadeirão está fortemente marcado na memória discursiva em relação à Bruxa, lembrando que memória discursiva é o lugar dos já ditos, do recorte dos sentidos para a atualização e a elaboração de enunciados. O caldeirão aparece nas sdrs 1, 2, 3 e 7 como o instrumento principal de concretização da maldade da Bruxa - o momento em que ela atinge o seu principal objetivo: cozinhar as criancinhas. Mais uma vez ocorre a paráfrase, o retorno ao discurso da igreja via versões dos contos de fadas que sacramentam a Bruxa demoníaca, o que transforma o caldeirão de poções da feiticeira em perigo para a humanidade, posto que nele se produzem vários preparos capazes de contaminar as pessoas do "bem", os "bons" cristãos.

A reiteração dos sentidos histórico-sociais referenciados à Bruxa leva a Orlandi (1999, p. 37), que ressalta que

na análise do discurso distinguimos o que é criatividade do que é produtividade. A "criação" em sua dimensão técnica é produtividade, reiteração de processos já cristalizados. Regida pelo processo parafrástico, a produtividade mantém o homem num retorno constante ao mesmo espaço dizível: produz a variedade do mesmo. 
A capacidade de perversidade da Bruxa ganha maior destaque no discurso da criança por se concretizar em um caldeirão, pois não pode haver maldade maior do que transformar seres inocentes em comida e queimá-los vivos, para, depois, degustá-los a partir de uma poção mágica de magia negra. O caldeirão, dessa forma, é tão temido quanto a própria discípula da besta, mas será que ele é apenas uma metáfora de algo que causa muito mais horror? Veremos daqui a pouco.

\section{A criança e a Bruxa: um convite à fantasia}

A PS1 consagra a ideia de Bruxa como diabólica e, ao mesmo tempo, assegura o imaginário da criança em relação ao mágico, a um ser que, com poderes do além, é capaz de interferir na vida das pessoas, como é possível perceber nas demais srds que mantêm a Bruxa como demoníaca nas suas condutas e rituais:

Sdr 9 a bruxinha, ela vai na casa de uma bruxa, daí a bruxa faz tipo um bolinho assim, daí pra mãe dela, daí a princesa foi busca pra ela, pra mãe dela melhorar, daí ela foi lá, quando ela chegou em casa a mãe dela tava boa, daí ela deu aquele bolo pra ela ficar mais boa, né? Daí ela comeu aquele bolo, aí ela ficou mal, e daí ela virou um Urso.

Sdr 10 Pesquisadora: E a bruxa é sempre ruim?

Criança: Sim.

Pesquisadora: Sempre ruim?

Criança: Na lua cheia também.

Pesquisadora: - Na lua cheia, por que na lua cheia?

Criança: Porque sim, às vez tem um luau lá perto de casa que é cheio de bruxa.

Na sdr 9 o diferente emerge e a criatividade em relação à personagem Bruxa ganha uma multiplicidade de sentidos, pois a bruxinha é boa (busca um bolinho na casa da Bruxa para sua mãe ficar melhor) e a Bruxa é malvada (o bolinho dela faz a mãe da bruxinha ficar mal e virar urso). Dessa forma, a bruxa, representada como criança - a bruxinha -, não é malvada; ela apenas quer que sua mãe melhore. A Bruxa adulta é ruim; promove a maldade por meio do alimento ofertado à bruxinha.

A imaginação dá espaço para a criatividade pela formulação de uma historinha nova, a partir da paráfrase dos contos de fadas em que as Bruxas têm o poder de transformar pessoas em animais. O interessante é que a Bruxa em forma de criança gera outros significados para o sujeito, levando a crer que sua FD não dá espaço para representação de uma criança malvada.

Essa reinscrição do conceito cristão de criança apoia-se na paráfrase desse sujeito como ser inocente que, mesmo na forma de Bruxa, não pode/não deve ser ruim. Já a Bruxa adulta está inscrita como perversa no interdiscurso.

A imaginação da criança em torno da personagem Bruxa está imersa na fantasia, na relação com o mágico e com os poderes sobrenaturais, consagrando as versões dos contos de fadas a partir do Grimm, como também é possível perceber na sdr 10, em que em noite de lua cheia as Bruxas fazem luau perto da casa da criança. Aqui temos a paráfrase do Sabbath, ritual de adoração aos Deuses por culturas aldeãs, e que foi transformado pela Inquisição em ritual de adoração ao demônio pelas Bruxas. A lua cheia, 
também envolta de misticismo na nossa cultura, aparece no discurso como o momento ideal para que as Bruxas se encontrem perto da casa da criança, o que pode ser uma metáfora para encontros de jovens que usam drogas e fazem barulho, por exemplo.

Bruxa e universo fantástico caminham lado a lado a partir do devaneio do sujeito, que recria histórias dessa personagem, representando-a em seu mundo de reinscrições daquilo que está presente na FD dominante. Podemos regatar, aqui, a função-autor, na qual o sujeito necessita reconfirgurar essa multiplicidade de representações na organização "dessa dispersão num todo coerente, apresentando-se como autor, responsável pela unidade e coerência do que diz" (ORLANDI, 1999, p. 76).

Todo esse processo tem origem na paráfrase, na constituição de um sujeito na história, que se origina, por sua vez, daquilo que o pré-constitui e daquilo que sustenta seu interdiscurso (e seu discurso), e que, também, é produtor de múltiplos sentidos, a partir da criação na produção da linguagem, o que permite a polissemia.

Produtividade e criatividade incidem e se entrelaçam no discurso, possibilitando a existência do sujeito e sua crença na autonomia, na liberdade daquilo que diz e na criação de suas ideias.

\section{O escuro e a feiura: outros pilares da Bruxa demoníaca}

Entre os aspectos instigantes das entrevistas está o estereótipo da Bruxa que, como ser do inferno, deve ser feia e usar roupa escura, como podemos visualizar nas próximas sdrs:

Sdr 11 Pesquisadora: - Que cor é a bruxa?

Criança: - Preto.

Sdr 12 - É feia.

Sdr 13 - Ela tem um chapéu e bota aqueles casacão de bruxa mesmo.

Mais uma vez o maniqueísmo retorna ao discurso, abrindo um leque de efeitos de sentido para a concepção dual da existência humana: o mau não pode ser bom, assim como não pode ser bonito; quem é ruim é feio, veste preto, não pode vestir colorido, pois as cores radiantes são para pessoas do bem, para as princesas, para as crianças.

Ainda no âmbito da produtividade, com variações do mesmo, as crianças relatam aspectos do que apreenderam via alguns contos de fadas e historinhas que trazem a dualidade. Esse aspecto reforça os estudos de Pêcheux (1995, p. 162) sobre formação ideológica:

O funcionamento da ideologia em geral como interpelação dos indivíduos em sujeitos (e, especificamente, em sujeitos de seu discurso) se realiza através do complexo das formações ideológicas (e, especificamente, através do interdiscurso intrincando nesse complexo) e fornece "a cada sujeito" sua "realidade", enquanto sistema de evidências e de significações percebidas - aceitas - experimentadas.

Trata-se da liberdade limitada do sujeito em relação ao seu próprio discurso, uma vez que, assujeitado, reproduz o que ficou convencionalmente determinado, que seria a cor e a cara da maldade, da tristeza e, até mesmo, do luto: o preto, representando o escuro, ou a escuridão, as trevas, assim como a feiura. Aqui incide a "ordem da história enquanto mundo, material constitutivo que representa de modo simbólico a materiali- 
dade dos processos sociais" (DORNELES, 2003, p. 41). A Bruxa, como ser do demônio, não poderia utilizar outra cor em sua vestimenta que não o preto; o branco da paz é para os bons, para os anjos.

A cultura eclesiástica é tão dominante no processo histórico que consegue, até mesmo, definir padrões de beleza para o bem e para o mal, transferindo esses padrões estéticos para os contos populares acerca da floresta e seus perigos, que, mais tarde, são transportados para alguns contos de fadas. A professora PS1 sustenta a velha fórmula textualizada em vários contos, a de um ser horripilante, feio, tenebroso, que veste preto, usa aquele chapéu e capa. Se, porém, considerarmos que "os sentidos são aves, eles migram" (PETRI, 2010, p. 25); para onde podem ter voado os sentidos da bruxa?

\section{Silenciamento e fala - PS2}

Ao realizar as entrevistas encontramos uma dificuldade preocupante: a de fazer a maioria das crianças responder a partir da fala e não da cabeça balançando, para dizer que sim ou que não. Fazer com que interagissem a partir da voz foi um grande desafio, como é possível perceber nas srds que seguem:

Sdr 14 Pesquisadora: - Conta pra tia, tu gosta de ler historinha?

Criança: Disse sim com a cabeça (chorando).

Sdr 15 Pesquisadora: - Tu gosta de ler historinha?

Criança: Balançou a cabeça, dizendo que sim.

Pesquisadora: - Tu pode responder em voz alta pra tia?

Criança: Balançou a cabeça, dizendo que sim.

Sdr 16 Pesquisadora: - Conta pra tia, tu gosta de ler historinha?

Criança: Disse sim com a cabeça.

Sdr 17 Pesquisadora: Queria saber se tu gosta de historinha.

Criança: Disse que sim com a cabeça.

Pesquisadora: Sim? Tu lê livrinho aqui na escola?

Criança: Disse sim com a cabeça.

Sdr 18: Como é bruxa dos contos de fadas?

Criança: Silêncio total.

Sdr 19: O que é viver feliz para sempre?

Criança: sinal de não com a cabeça.

Sdr 20: A Bruxa é sempre malvada?

Criança: Silêncio total.

Sdr 21: Qual o seu livrinho preferido?

Criança: Silêncio total.

A ausência de voz e a adoção do gesto com a cabeça como forma de comunicação causa inquietação, pelo fato de ter se repetido na maioria das entrevistas, sendo difícil alcançar a interação com a criança pela fala. $\mathrm{O}$ que isso representa no discurso? $\mathrm{O}$ que a não voz quer dizer?

Pensando sobre essas questões, chegamos à professora PS2 - Silencimento e fala. Que "Bruxa" comeu a língua das crianças? A escola, o professor, a formação social? 
A AD estuda o silêncio na perspectiva da relação um e múltiplo, na qual é necessário silenciar o múltiplo para que o um fale; e quando o um não fala com a voz, mas com a cabeça? Orlandi (1995, p. 105) ressalta a existência de uma outra forma de silêncio: "o silêncio local" (o da censura), da interdição do dizer, mas a ausência de voz diz muito. Não temos aqui o silêncio, mas um silenciamento que parece ter relação direta com a posição social dada, com a reprodução da classe de origem, com a autoidentificação no ambiente escolar, como aquele que não pode/não deve dizer.

Essa ausência de voz parece uma tomada de posição de um sujeito com espaço estreito para o exercício da oralidade, que se coloca em lugar desprivilegiado no ato da comunicação, por não se sentir seguro o suficiente para dialogar com um adulto ou por considerar, em razão da sua FD, que não tem esse direito. Chegamos a tal conclusão pela associação desse silenciamento com a realidade do acesso limitado à leitura e ao mundo do faz de conta e do brincar dentro e fora da escola, o que foi possível perceber a partir das entrevistas e do conhecimento restrito das crianças acerca dos contos de fadas. Considerando a idade dos entrevistados na faixa etária de 6 a 11 anos, o repertório de leitura ao qual demonstraram ter acesso não dá espaço aos planos mais profundos da imaginação, que permitem a crença dos cavalos que voam e dos animais que falam, planos estes necessários à infância e que sustentam a habilidade de interpretação de textos, da criação e da inovação.

O silenciamento materializa um ambiente educacional que não privilegia o pensamento crítico-reflexivo, a recriação e a ressignificação dos contos. Movidos pelo medo de talvez responder errado, preferem assegurar-se por meio de gestos, aspecto que se evidencia na dificuldade de trazê-los para a fala.

Aqui estão as formações imaginárias, as projeções que o sujeito faz do outro e, desde as quais, formula seus enunciados.

Também, podemos destacar a atuação dos Aparelhos Ideológicos de Estado na formação ideológica do sujeito, lembrando que, para Pêcheux (1995, p. 144), "as ideologias não são feitas de ideias, mas de práticas."

Como estamos falando de crianças, as relações de desigualdade-subordinação explicitam-se ainda mais, materializando-se na ausência da voz. Segundo Pêcheux (1995, p. 146), a partir de seu estudo sobre a teoria de Althusser (1985),

Compreende-se, então, por que em sua materialidade concreta, a instância ideológica existe sob a forma de formações ideológicas (referidas aos aparelhos ideológicos de Estado), que, ao mesmo tempo, possuem caráter "regional" e comportam posições de classe: os "objetos" ideológicos são sempre fornecidos ao mesmo tempo que "a maneira de se servir a eles" - seu "sentido", isto é, sua orientação, ou seja, os interesses de classe aos quais eles servem -, o que se pode comentar dizendo que as ideologias práticas são práticas de classes (de luta de classes), "posições de classe" que existam de modo abstrato e que sejam então aplicadas aos diferentes "objetos" ideológicos regionais das situações concretas, na Escola, na Família, etc. É, aí, na verdade, que o vínculo contraditório entre reprodução e transformação das relações de produção se liga ao nível ideológico, na medida em que não são os "objetos" ideológicos regionais tomados um a um, mas sim o 
próprio desmembramento em regiões (Deus, a Moral, a Lei, a Justiça, a Família, o Saber, etc.) e as relações de desigualdade-subordinação entre essas regiões que constituem a cena da luta ideológica de classes.

Sendo a cultura a morada do sujeito, altamente influenciada pelos AIEs, nesse caso principalmente a escola e a família, o sujeito se recolhe à sua realidade de criança, que não pode/não deve dizer com medo de errar, ou de mentir, de interagir com um estranho que não conhece e que pode vir a julgá-lo de alguma forma. O melhor é silenciar.

Conhecimentos culturalmente produzidos como naturais, os efeitos de evidência, como a subordinação da criança a um adulto, como se o seu espaço de fala não devesse ser respeitado, ou talvez nem existir, emergem nessas ocasiões, em que momentos são destinados para o conhecimento desse sujeito.

Essas posturas questionam nosso modelo de sociedade, nosso papel enquanto pais, educadores e cidadãos. Será que o sistema contribui para uma escola que trabaIhe pela emancipação do sujeito e pelo desenvolvimento da linguagem para que possa intervir nos mais diversos espaços sociais? Como pode a escola silenciar? Estaria acontecendo o que nos aponta Scherer (2007, p. 347): "ela consegue despovoar a língua. Purificando-a. Descarnando-a. Não deixando mais nada do que os seus ossos". Esse efeito contrário ao que deveria ser o seu principal papel - a emancipação -, a partir do trabaIho com uma língua que é fluida, será discutido a seguir.

\section{A língua que cala é a bruxa que fala}

Como foi possível perceber, no conto da vida real dos sujeitos pesquisados a Bruxa malvada das crianças parece ser a concepção imaginária da língua reproduzida pelo AIE Escola, aquela que busca definir quem sabe e quem não tem conhecimento da língua materna, medindo as habilidades dos seus usuários não por competências linguísticas, mas pela descrição da língua. Essa realidade cala, corta a língua, queima as oportunidades de mobilidade social, silencia os alunos, como podemos perceber nas sequências discursivas anteriores e nas próximas.

Sdr 22 Pesquisadora - Tu já ouviu falar nos contos de fadas?

Criança: Disse que não com cabeça.

Pesquisadora: - Os três porquinhos é um conto de fadas?

Criança: Disse que não com a cabeça.

Sdr 23 Pesquisadora: - Tu gosta de ler historinha?

Criança: Disse que sim com a cabeça.

Pesquisadora: E qual que tu mais gosta?

Criança: Do cavalo.

Pesquisadora: Do cavalo, é? E quantos aninhos tu tem?

Criança: Não sei.

Pesquisadora: Não sabe, mas eu pergunto para tua mãe depois, não tem problema. Tá, e só gosta do cavalo?

Criança: Disse que sim com a cabeça.

Sdr 24: Qual o seu personagem preferido dos contos de fadas?

Criança: Silêncio total.

Sdr 25: A Bruxa pode ser boa?

Criança: Silêncio total. 
Esse silenciamento promove reflexões acerca do trabalho de uma ordem impositiva e seletiva no ensino da Língua, que acaba consagrando o objetivo dos Aparelhos Ideológicos do Estado: impor o discurso das classes dominantes, censurando, a partir da posição de autoridade que ocupam, a fala daqueles que julgam que não precisam ter voz. A língua imaginária colabora para essa manipulação, uma vez que não valoriza a cultura do sujeito, manifesta por uma língua que é viva, que está na rua, que se modifica com a história e que é calada dentro da Escola, ejetando diversos alunos dos bancos escolares e limitando seus espaços na sociedade.

Seria o jogo dos sentidos; a repetição do sentido de Bruxa como demoníaca no diferente, não nos contos de fadas, mas na vida real, na escola. Temos nos discursos dos entrevistados a Bruxa como uma metáfora do medo, ou seja, manutenção de situações que fazem o sujeito permanecer com medo, com receio de falar, temendo a censura, a correção. Antes da punição é melhor calar.

A inclusão acaba sendo uma fantasia na maioria das escolas que promove apenas a inserção dos alunos, lançando-os nos espaços educacionais sem dar conta da heterogeneidade, especialmente quando tratamos das desigualdades sociais.

As crianças pesquisadas experimentam diariamente inúmeras dificuldades, de diversas ordens, na vida pessoal e na escola. O aparelho ideológico escola, quando não atua pelo direito à infância, ao mundo do faz de conta, ao brincar para aprender, ao se movimentar para aprender, contribui com o silenciamento, com a interdição e com a limitação do dizer, definindo quem pode/deve aprender.

O caldeirão, presente na maioria dos discursos das crianças, não está nos contos de fadas, mas nas experiências reais, quando são queimadas todas as possibilidades de embarcarem no mundo mágico da imaginação, no devaneio de criança em busca de animais que falam, de pessoas com poderes mágicos, de seres capazes de viajar no tempo, como podemos perceber retomando algumas sdrs:

Sdr 1 Feia, pega, bota no caldeirão. Ela arródia. Ela come.

Sdr 2 Ela tem a varinha dela, ela coloca a gente dentro do caldeirão, ela acende o fogo, quema, ela mata as crianças.

Sdr 3 Ela bota a gente no caldeirão. Ela meche pra fazer bruxaria.

A negação do direito à expressão pela língua fluida, considerando a diversidade cultural e social, é o caldeirão do silêncio, é a própria negação à infância e ao direito de mobilidade social, se considerarmos que a ausência de voz das crianças no presente pode ser o indício de um silenciamento futuro, de uma voz que se cala por acreditar que a classe de origem não permite que fale.

O silenciamento, refletido na opção pela ausência da fala, também mostra um sujeito que é criança como ser físico a partir de seu RG, mas que não, necessariamente, está tendo acesso à infância, ao tempo de brincar, de viver o mundo do faz de conta, de conhecer o universo de leitura e prazer, de contar suas próprias versões dos contos, de conhecer, a partir deles, novas possibilidades para o "bem" e para o "mal" e de, até mesmo, questionar se essa dualidade existe. O que vemos no contexto escolar é, muitas vezes, a mediação da leitura trabalhada de forma nada atrativa, sem encantamento para o aluno, sem possiblidade de fugir da realidade e procurar novos sentidos para as 
suas experiências; realidade esta que boicota a cultura da leitura e, consequentemente, a competência linguística do sujeito como ator social que utiliza a língua portuguesa de forma autônoma, compreende, interpreta, critica e reflete sobre o que lê. O que vemos, em todos os graus de ensino, é um alto nível de alfabetismo funcional, de pessoas que decodificam as letras, mas não compreendem o que estão lendo e não produzem sentidos para além dos textos, e isso é um limitador, também, para a oralidade, levando em conta que damos para os enunciados apenas o que temos na nossa Formação Discursiva.

Conforme nos mostra Escobar (1979. p. 105),

A eficácia desse aparelho de Estado é dada na prática dos AIE em diferentes formas de realizar um "efeito ideológico de sujeito" nos corpos biológicos que a procriação oferta e que as disciplinas estabelecem, reproduzindo as classes de origem.

A Escola, ao negar seu papel emancipador, selecionando por meio da própria língua materna os que vão e os que ficam, aparece como o inquisidor, aquele que define quem pode se libertar e quem deve ser enforcado ou queimar na fogueira, conforme o jogo de interesses da classe dominante. Retomamos Escobar (1979, p. 185) e seu alerta sobre falsas ciências que, veiculadas aos Aparelhos Ideológicos do Estado, funcionam como "máquinas de classes dominantes, isto é, como um aparelho de classe que no interior da luta de classes encaminha os interesses dos donos do capital".

A instituição escolar, uma das protagonistas dos AIEs, ao trabalhar a partir da concepção de língua imaginária acaba classificando quem pode/deve viver na sociedade crítica e aqueles que irão permanecer como engrenagens não pensantes da sociedade funcionalista, aqueles que Zé Ramalho lembrou na letra de "Vida de Gado", que farão "parte dessa massa, que passa nos projetos, do futuro", que darão muito mais do que irão receber. Sobre essa posição social dada, Escobar (1979, p. 185) lembra que

Nas sociedades capitalistas as classes ficam escamoteadas em princípio, seja no "automatismo" relativo da dimensão econômica (salário/mais-valia) seja na marcada independência que ganha o Estado. O que significa dizer que o Estado, quase todo ele somente ARE, das sociedades pré-capitalistas, obrigado que era a intervir permanentemente na economia para assegurar a expropriação do sobre-trabalho, dá lugar agora a um tipo de Estado menos recluso em sua ação repressiva e mais aberto ao jogo da inculcação ideológica. E isso aliás conforme as determinações mesmas das novas relações de produção obrigadas a um tipo de agente social bem mais "realizado" política e ideologicamente e que exigirá formas "institucionais" novas tais como a Escola, a família conjugal, o direito burguês, o aparelho médico etc.

A herança social deve colar no sujeito e impregná-lo a ponto de extinguir qualquer alternativa de mobilidade social. Seja na Escola, seja na família, o discurso ideal para as classes dominantes é o que segmenta o conhecimento, distribuindo-o nas dosagens certas para as finalidades dos detentores do capital. Essa definição, logicamente, começa na criança, mostrando, desde cedo, o seu lugar no espaço, assegurando que não encontre sua imaginação em planos mais profundos, capazes de libertar e emancipar mentes, aspecto refletido nas sdrs analisadas. 


\section{A língua engolida pela Escola}

As situações de silenciamento apresentadas nesta pesquisa, levam a uma reflexão acerca do imaginário produzido pela escola do que seria a língua ideal para as crianças: aquela que autoriza o sujeito a falar nos espaços sociais dados. A ideia de língua que está em primeiro plano para os entrevistados é aquela "domesticada, submetida à escolarização", como nos aponta Dorneles (2011, p. 35):

A relação que estabelecemos com a escola diz respeito ao fato de que ela tem sido fundamental para definir quem sabe e quem não sabe a língua materna. Tanto as avaliações escolares internas quanto as avaliações externas apontam deficiências dos estudantes em relação ao domínio dos conteúdos linguísticos veiculados pela escola. Sabemos que muitos dos instrumentos de avaliação refletem a cobrança não de um saber linguístico, mas de um conhecimento acerca da descrição da língua. Essa realidade, além de expurgar diversas crianças e adolescentes do processo escolar, contribui para construção do imaginário dessas famílias em relação a um não-lugar também como condição de falante da língua materna.

Esse não lugar se reflete nas sdrs:

Sdr 26 Pesquisadora: e quantos aninhos tu tem?

Criança: não sei

Sdr 27 Pesquisadora: ta, e tu só gosta do cavalo?

Criança: Disse que sim com a cabeça

Sdr 28 Pesquisadora: Aquela tromba dele é grande.

Criança: Disse que sim com a cabeça

Pesquisadora: tu já ouviu a historinha que tem a bruxa?

Criança: Disse que sim com a cabeça

Sdr 29 Pesquisadora: só quando a lua fica pequena a bruxa é boa? E quando a lua fica cheia a bruxa é ruim?

Criança: Disse sim com a cabeça

Crianças de oito anos que não sabem dizer a idade, crianças de 6 a 11 anos emudecidas. Podemos enxergar nessas sdrs o trabalho da língua imaginária, aquela desenhada pela gramática normativa, aquela que está inacessível para muitos alunos.

Enquanto não ampliarmos a concepção de língua para aquela que é "incompleta, em movimento, aberta à exterioridade que lhe é constitutiva" (PETRI, 2011, p. 26), seremos como parte dos AIEs e reproduziremos seu principal objetivo, separar corpos no espaço pela força do capital, como nos aponta Orlandi (1988) em sua pesquisa sobre a tentativa de apagamento das línguas primitivas na constituição da língua portuguesa.

Não agimos diferente no ensino de línguas. Ao focarmos os estudos na gramática, dicionário e livro didático, reproduzimos a visão da classe dominante e negamos o acesso à língua que é nossa, que está na história, que adquirimos muito antes de irmos à escola. Coracini (2007, p. 140-141) fortalece essa ideia lembrando que "em vez de uma aproximação, o ensino da 'norma culta' levou a um distanciamento, escavando um fosso entre o sujeito e a língua, que se vêem, assim, isolados um do outro" a partir de uma consciência de diferenças na fala que mostram as disparidades sociais, consequência direta da visão dicotômica que isolou a língua do meio social. 
Esse binarismo entre língua e fala perdura até hoje e impera no ensino, higienizando o sistema, deixando a área limpa para o livre-controle dos AIEs. Conforme Coracini $(2007$, p. 17), "o sujeito é também alteridade, carrega em si o outro, o estranho, que o transforma e é transformado por ele", é facilmente governado por aqueles que têm "autoridade legitimada". A escola tem essa autoridade e seus processos de seleção autenticam o espaço de cada corpo em posições sociais dadas.

Tanto a bruxa da inquisição, feiticeiras e mulheres com conhecimentos curativos, transformadas em demônios, e a bruxa da criança pesquisada, essa língua imaginária que "descarna" a língua (SCHERER, 2007), são fabricações dos AIEs para a manutenção do controle sobre as classes populares. Cada bruxa a seu tempo é fonte ou metáfora do medo; medo produzido, cultivado e divulgado para a garantia do oportuno silêncio da interdição, materializado nas sdrs estudadas.

É a "bruxa" que fala, é a "bruxa" que cala, é a "bruxa" que queima, é a "bruxa" que coloca no caldeirão. Enquanto essa "bruxa" toma a cena, os bastidores ficam livres para a dominação, para o exercício do poder disciplinar, para que a língua das crianças seja cortada na raiz.

\section{Jogando o último ingrediente no caldeirão: o funcionamento discursivo}

Ao serem chamados a falar, a expandir seus pensamentos sobre os contos de fadas, interagindo com a pesquisadora, a maioria das crianças emudeceu. Não se permitindo falar, essas crianças marcam o lugar da exclusão e o lugar da escola, por intermédio do trabalho com a língua imaginária, como operadora da memória social.

Percebemos isso na localização das posições-sujeito: PS1 - Bruxa demoníaca e PS2 - Silenciamento e fala. Esses "vários" do "mesmo", os diferentes lugares habitados pelo sujeito em sua morada, a cultura e a formação social, deixam em primeiro plano a paráfrase da inquisição e de alguns contos de fadas em relação à personagem Bruxa: ela é malvada (a não ser na forma de criança), feia e tem poderes sobrenaturais utilizados para o mal. A posição de não voz diz respeito às formações imaginárias e ideológicas, às antecipações em relação à entrevistadora e à ideia de que, enquanto criança, meus espaços de fala são limitados, dentro de uma formação social dada ou por considerar que "ao falar, posso errar,"

Está presente a paráfrase dos discursos de instâncias com poder legitimado no silenciamento das crianças, caladas pela própria língua materna, que, ao invés de promover a autonomia, distancia o sujeito da sua utilização. Aqui estão as "regras de projeção" (PÊCHEUX, 1993, p. 82), as formações imaginárias que definem o que devo/posso falar, conforme a posição social dada e daquele a quem falo.

A paráfrase aqui reproduz os objetivos dos Aparelhos Ideológicos de Estado, seja da bruxa da inquisição ou da bruxa língua imaginária, divulgando o medo em forma de censura com o objetivo central de calar a voz, de tentar impedir a mobilidade social, aspecto que também se materializa na gramática normativa, dicionários e livros didáticos. A versão oficial aparece como imperativa e sacramentada nos bancos escolares, ejetando aqueles que não se enquadram nos padrões desejados. 
A polissemia está na heterogeneidade da PS1 - Bruxa demoníaca, mostrando que a mesma posição-sujeito pode abrigar diferentes vertentes. A conduta social da bruxa, seus poderes sobrenaturais e sua estética mostram o deslize de sentidos acerca da personagem, mas todos os voos retornam à origem: a imagem da Bruxa como demoníaca.

O capital é o alicerce que determina os fenômenos sociais e históricos, segundo Marx. Esse princípio do Materialismo Histórico está na trajetória da camponesa fabricada como diabo, cuja imagem, até hoje, é representada pelo mal na memória discursiva.

Os processos de paráfrase e polissemia estão presentes no funcionamento discursivo, mostrando a relação do sujeito criança com a exterioridade e como a historicidade produz esse sujeito, especialmente na sua relação com a escola.

\section{CONSIDERAÇÕES FINAIS}

Os contos de fadas apresentam enredos ricos em significados e personagens que se incorporam à memória coletiva, afetando o discurso daqueles que têm acesso a eles. A infância, normalmente, é a fase de primeiro contato com essas leituras, e perceber como o sujeito criança enxerga para além desses textos é uma proposta de pesquisa que clama por respostas, tendo em vista que se trata do direcionamento discursivo do nosso adulto do futuro.

A Bruxa, personagem carregada de significados, levando em consideração a formação dual da existência humana e as consequentes concepções de bem e mal, certo e errado, representa um campo fértil de investigação.

Nas primeiras análises verificamos que a paráfrase da Bruxa está legitimada na relação sujeito criança/personagem Bruxa, que retoma, em seus discursos, estereótipos historicamente atribuídos à essa personagem: diabólica, feia e com poderes mágicos para fazer o mal. Essas vertentes sustentam a Posição-sujeito Bruxa demoníaca - PS1, uma fabricação da Inquisição, largamente presente nos contos de fadas.

Também localizamos a Posição-sujeito Silenciamento e fala - PS2, na qual o sujeito prefere não se manifestar por meio da voz, promovendo reflexões acerca do que o não espaço de fala representa em sua formação social. Esse silenciamento diz muito sobre o lugar que o sujeito imagina que deve/pode ocupar em seus espaços de enunciação e sobre o trabalho da escola a partir de uma concepção de língua imaginária, aquela que tem como base somente a norma culta, o que distancia o aluno da sua própria língua materna.

Nesse ponto, o trabalho ganhou novos direcionamentos, mostrando a incidência maior da paráfrase no funcionamento discursivo e evidenciando que a relação sujeito criança/personagem Bruxa é constituída por uma sobreposição de imagens que remonta um cenário de medo e censura desenhado na Idade Média, e que serve de metáfora para o temor da fala, resultado de um trabalho que não considera a língua como algo vivo na história. Assim, atingimos o principal objetivo desta pesquisa: desvelar o funcionamento discursivo a partir da análise dos efeitos de sentido constituídos na relação personagem Bruxa/sujeito criança. 
Quanto aos objetivos de refletir sobre os efeitos de sentido da Bruxaria para as práticas socioculturais da sociedade interiorana do Rio Grande do Sul, verificar a inscrição de sentidos no interdiscurso relativo à Bruxaria e analisar o percurso dos sentidos da designação Bruxa na formação social também interiorana do Rio Grande do Sul, verificamos que os sentidos acompanham o discurso cristão. A Bruxa da FD das crianças entrevistadas é produção tanto da Inquisição, ou seja, é malvada e perversa, quanto de vários contos de fadas dos Grimm, e tem poderes sobrenaturais utilizados para o mal.

Antes de finalizar, é importante retomar o que Dorneles $(2011, p .45)$ ressalta sobre os catadores quanto à preocupação com as condições ambientais de moradia desses profissionais, uma vez que compartilham da mesma realidade das crianças entrevistadas. A autora salienta que:

"aglomeram-se muitos disputando um mesmo produto: rejeitos ou dejetos da sociedade de consumo." São homens, mulheres, crianças, urubus, porcos, todos quase em condições de igualdade. Ainda não entraram no litígio. Existe uma invisibilidade que não os individualiza enquanto grupo humano nessa disputa pelos restos.

A disputa pelos restos não está somente localizada nas condições de trabalho e moradia, mas nossa pesquisa mostrou que essa disputa também está na escola. Essas crianças, além de partilharem com suas famílias condições que se confundem entre humanas e desumanas, ainda estão submetidas ao trabalho seletivo do AIE Escola , capaz de "cortar" a língua.

No conto de fadas da vida real a Bruxa é muito pior, pois nesse enredo não existe possibilidade de virar o jogo como em "João e Maria" e jogá-la no forno. Aqui, a nossa Bruxa é tão poderosa que ainda jogará muitas crianças no caldeirão. Por isso, vale um convite para subirmos na vassoura, voarmos por essa realidade e buscarmos poções que transformem o seu feitiço, pois

Quem ocupa o trono tem culpa
Quem oculta o crime também
Quem duvida da vida tem culpa
Quem evita a dúvida também tem (Engenheiros do Hawaii).

\section{REFERÊNCIAS}

ALTHUSSER, Louis. Aparelhos ideológicos de Estado: nota sobre os Aparelhos Ideológicos de Estado (AIE). Tradução Walter José Evangelista e Maria Laura Viveiros de Castro. Introdução crítica de José Augusto Guilhon Albuquerque. Rio de Janeiro: Edições Graal, 1985.

BETTELHEIM, Bruno. A psicanálise dos contos de fadas. Rio de Janeiro: Paz e Terra, 1996.

CORACINI, Maria José R. F. A celebração do outro na constituição da identidade. In: Organon/UFRS, Instituto de Letras, v. 17, n. 35, 2003.

CORACINI, Maria José R. F. A celebração do outro: arquivo, memória e identidade: línguas (materna e estrangeira), pluralismo e tradução. Campinas, SP: Mercado das Letras, 2007.

DORNELES, Elizabeth Fontoura. Da germinação da semente à colheita do grão: análise do funcionamento das relações de identificação na formação discursiva dominante do assentado. 1998. Dissertação (Mestrado) - Porto Alegre: UFRGS, 1998.

DORNELES, Elizabeth Fontoura. Discurso sobre a língua e a constituição da língua na escola. In: SCHONS, Carme Regina; CAZARIN, Ercília Ana (org.). Língua, escola e mídia: en(tre)laçando teorias, conceitos e metodologias. Passo Fundo: Ed. Universidade de Passo Fundo, 2011.

DORNELES, Elizabeth Fontoura. Memória, linguagem e história do festival nativista. In: Organon/UFRS, Instituto de Letras, v. 17, n. 35, 2003. 
ESCOBAR, Carlos Henrique. Da categoria da cultura: do aparelho cultural do Estado. In: ENCONTROS COM A CIVILIZAÇÃO BRASILEIRA. Rio de Janeiro: Civilização Brasileira, 1979. V. 16.

FERREIRA, Maria Cristina Leandro. Análise do discurso e suas interfaces: o lugar do sujeito na trama do discurso. In: Organon/UFRS, Instituto de Letras, v. 24, n. 48, 2010.

INDURSKY, Freda. Lula lá: estrutura e acontecimento. In: Organon/UFRS, Instituto de Letras, v. 17, n. 35, 2003.

ORLANDI, Eni P. A linguagem e o seu funcionamento. As formas do discurso. 4. ed. Campinas, SP: Pontes, 2003.

ORLANDI, Eni P. Análise de discurso: princípios e procedimentos. Campinas, SP: Pontes, 1999.

ORLANDI, Eni P. As formas do silêncio: no movimento dos sentidos. Campinas: Editora da Unicamp, 1995.

ORLANDI, Eni P. Interpretação: autoria, leitura e efeitos do trabalho simbólico. Rio de Janeiro: Vozes, 1996.

ORLANDI, Eni P. (org.). Política linguística na América Latina. Campinas: Pontes, 1988.

PÊCHEUX, M. Análise Automática do Discurso (AAD-69). Parte I, In: GADET, F.; HAK, T. Por uma análise automática do discurso. Campinas, SP: Editora da Unicamp, 1993.

PÊCHEUX, M. Semântica e discurso: uma crítica à afirmação do óbvio. Campinas, SP: Editora da Unicamp, 1995.

PETRI, Verli. Discurso sobre a língua e a constituição da língua na escola. In: SCHONS, Carme Regina; CAZARIN, Ercília Ana (org.). Língua, escola e mídia: en(tre)laçando teorias, conceitos e metodologias. Passo Fundo: Ed. Universidade de Passo Fundo, 2011.

PETRI, Verli. Um outro olhar sobre o dicionário: a produção de sentidos. Santa Maria: PPGL-Editores, 2010. SAVIANI, Dermeval. Pedagogia histórico-crítica: primeiras aproximações. 10. ed. rev. Campinas, SP: Autores Associados, 2008. (Coleção educação contemporânea).

SAVIANI, Dermeval. Trabalho e educação: fundamentos ontológicos e históricos. Rev. Bras. Educ., Rio de Janeiro, v. 12, n. 34, p. 152-165, apr. 2007. Disponível em: http://www.scielo.br/scielo.php?script=sci_arttext\&pid=S1413-24782007000100012\&lng=en\&nrm=iso. Acesso em: 5 mar. 2020. DOI: https://doi. org/10.1590/S1413-24782007000100012.

SCHERER, Amanda. A constituição do eu e do outro pela interpelação da língua pela língua na história do sujeito. In: INDURSKY, Freda; LEANDRO FERREIRA, Maria Cristina (org.). Análise do discurso no Brasil: mapeando conceitos, confrontando limites. São Carlos: Claraluz, 2007. 